
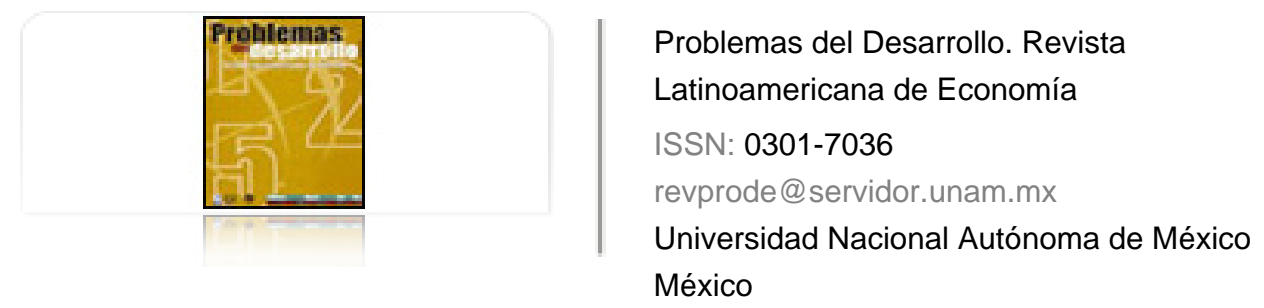

González Chávez, Gerardo

La globalización y el mercado de trabajo en México

Problemas del Desarrollo. Revista Latinoamericana de Economía, vol. 35, núm. 138, 2004, pp. 97-124

Universidad Nacional Autónoma de México

Distrito Federal, México

Disponible en: http://www.redalyc.org/articulo.oa?id=11825948006

- Cómo citar el artículo

- Número completo

- Más información del artículo

Página de la revista en redalyc.org

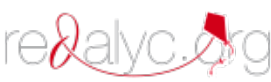

Sistema de Información Científica

Red de Revistas Científicas de América Latina, el Caribe, España y Portugal Proyecto académico sin fines de lucro, desarrollado bajo la iniciativa de acceso abierto 


\section{LA GLOBALIZACIÓN Y EL MERCAdO dE TRABAJO EN MÉXICO}

\section{Gerardo González Chávez*}

Fecha de recepción: 23 de agosto de 2004. Fecha de aceptación: 9 de septiembre de 2004.

\section{Resumen}

El propósito de este trabajo es analizar las condiciones en que se desarrolla el mercado laboral en el contexto de la globalización económica, en el cual existen graves problemas para el crecimiento del producto y la generación de los empleos que demanda la población trabajadora. Se analiza en detalle el incremento del desempleo y la necesidad de sobrevivencia que impulsan la contratación de trabajadores informales, sin las condiciones mínimas legales, y la manera en que esa informalidad se constituye en un receptor básico de la demanda de trabajo, ante un crecimiento limitado en la generación de empleos formales. Asimismo, el empleo precario se impone y se transforma en un elemento clave de la estructura actual del mercado de trabajo y un factor que deteriora los niveles de vida de los asalariados en el país.

Palabras clave: mercado laboral, flexibilización, empleo precario, empleo informal, competencia salarial.

\section{Abstract}

The purpose of this paper is to analyze the conditions in which the labor market develops in the context of economic globalization, where severe problems exist for the growth of production and the generation of employment demanded by the work force. It analyzes in detail the increase in unemployment and survival needs which drive the hiring of workers in the informal sector, without the minimum of legal conditions, and the way in which this informality is constituted in a basic receptor of labor demand, due to limited growth in the generation of formal sector employment. At the same time, precarious employment is imposed and transformed into a key factor in the present structure of the labor market and a factor that reduces the quality of life for wage-earners in the country.

Key words: labor market, flexibility, precarious employment, informal employment, wage competition.

* Investigador del IIEC-UNAM. 


\section{Résumé}

Le but de ce travail est d'analyser les conditions dans lesquelles se développe le marché du travail dans le contexte de la globalisation économique, dans lequel il y a de graves problèmes de par la croissance du produit et par la génération des emplois que demande la population travailleuse. On analyse le détail de la croissance de l'emploi et du besoin de survivre qui pousse à l'embauche de travailleurs informels, sans les conditions minimales légales, et la façon dont cette informalité se constitue comme récepteur essentiel de la demande de travail, face à une croissance limitée dans la génération d'emplois formels. De même, l'emploi précaire s'impose et se transforme dans un élément clé de la structure actuelle du marché du travail et dans un facteur qui détériore les niveaux de vie des salariés dans le pays.

Mots clés: Marché du travail, flexibilisation, emploi précaire, emploi informel, compétence salariale.

\section{Resumo}

Uma análise das condições em que se desenvolve o mercado de trabalho no contexto da globalização econômica, a qual ocasiona graves problemas para o crescimento do produto e para a geração dos empregos que demanda a população trabalhadora. Este trabalho apresenta um estudo detalhado do incremento do desemprego e da necessidade de sobrevivência que impulsiona a contratação de trabalhadores informais, sem as condições minimas legais. Revela, também, como essa informalidade se constitui em um receptor básico da demanda de trabalho, diante do crescimento limitado da geração de empregos formais. Mesmo assim, o emprego precário se impõe e se transforma em um elemento chave da estrutura atual do mercado de trabalho, se tornando um fator que deteriora os niveis de vida dos assalariados do pais.

Palavras-chaves: mercado trabalhista, flexibilização, emprego precário, emprego informal, competência salarial.

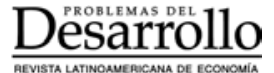




\section{Introducción}

$\mathrm{U}$

no de los problemas que más preocupa a la mayor parte de los trabajadores de nuestro país es la incertidumbre por obtener y conservar un empleo, debido al deterioro del mercado laboral; además de bajos salarios y pérdida de prestaciones sociales, las cuales se han visto cuestionadas por la apertura económica y la mayor integración de México al mercado mundial. Actualmente, en el contexto del neoliberalismo, se atraviesa uno de los momentos más difíciles para los asalariados, el cual viene acompañado por una crisis económica recurrente que repercute en la expansión del número de desempleados y facilita la imposición de condiciones laborales contrarias al interés de los trabajadores.

El mercado de trabajo en México se desarrolla en un contexto internacional de formación de grandes bloques económicos, el cual provoca fuertes impactos en la sociedad debido a políticas liberalizadoras establecidas en las relaciones laborales orientadas a programas de flexibilización. Estas últimas buscan la individualización de las condiciones de trabajo, la fragmentación de la mano de obra y de las jornadas, tras eliminar las conquistas obreras heredadas de un modelo anterior que otorgaba beneficios.

La transformación del modelo de acumulación obliga a los teóricos neoclásicos a fundamentar la flexibilización laboral. Éstos aseguran que el desempleo es producto de la rigidez de la contratación colectiva prevaleciente y que, para enfrentar la competencia, se deben eliminar obstáculos que impiden modificar libremente variables como salario, prestaciones y demás obligaciones —establecidas en la legislación laboral vigente- para incentivar la inversión y propiciar la generación de los empleos que se necesitan. Se deben cambiar, afirman, las relaciones laborales mediante el diálogo y la concertación entre trabajadores y patrones. Es necesario olvidar la lucha de clases e impulsar una nueva cultura laboral que imponga la productividad y la competitividad por encima de la justicia social por medio de la reforma a la Ley Federal del Trabajo para adecuarla a las actuales condiciones de competencia y asegurar al inversionista el abaratamiento de la mano de obra.

Las circunstancias en las cuales evolucionó el mercado de trabajo en el contexto internacional propician un incremento del desempleo. Aunque también hay un fuerte impulso a la generación de empleos pero en condiciones de contratación precaria, caracterizados oficialmente como empleos informales $-\mathrm{y}$ en particular aquellos que se ubican en micronegocios y autoempleo, los cuales se han constituido en elemento clave de la estructura actual del mercado laboral- . Pese a ello, no debemos perder de vista la migración y quienes en conjunto forman el mercado de trabajo mexicano.

\section{Desesarerstollo}


El objetivo fundamental de este estudio es entender, en el contexto de la globalización, cómo se ha establecido la flexibilidad en las relaciones de trabajo en México, y los efectos producidos en los niveles de ingreso y las condiciones laborales en general: garantías, derechos, compromisos y obligaciones; así como nuevas formas de negociación en la jornada de trabajo, días de descanso, disciplina en la empresa, prestaciones sociales, seguridad e higiene, implementos de mejoramiento del lugar de trabajo, intensidad y productividad, promoción y calificación. Se intenta destacar los efectos en cuanto a libertad sindical, derecho de huelga, prestaciones sociales e indemnizaciones, ${ }^{1}$ en un contexto cuya creación de empleos formales perdió vigor e incluso, en situaciones recesivas, muestra una disminución. Circunstancia difícil — a pesar de la ampliación de la masa de trabajadores ocupados en la informalidad con deterioro constante de su calidad de vida y de trabajo, con jornadas más extensas, menores ingresos, sin prestaciones- en el que parece ser el único camino para el creciente número de trabajadores de reciente incorporación al mercado laboral.

\section{Aspectos teóricos fundamentales acerca del mercado de trabajo}

Un análisis científico del mercado de trabajo debe rescatar la categoría de ejército industrial de reserva como un concepto aún vigente, que permita dar cuenta de las transformaciones que están ocurriendo con los trabajadores en nuestros días. ${ }^{2}$ Es necesario ubicar la fuerza de trabajo desde una perspectiva histórica que conciba el proceso de valoración en su conjunto: producción, distribución y consumo. Debe plantearse como una unidad de la acción económica en la cual se genera la riqueza nacional y el trabajo humano se convierte en la piedra de toque que explica la reproducción del capital.

En el mercado se establece una relación entre capital y trabajo en condiciones de oferta y demanda que se distribuye de manera diferenciada y de acuerdo con las condiciones de la inversión destinada al trabajo, en correspondencia con el gasto en medios de producción. A lo anterior Marx lo denominó “composición orgánica de capital” y, en esa relación, el mercado de trabajo adquirirá características particulares. Si la venta de la fuerza de trabajo se da en una situación favorable para los obreros, sus ingresos tenderán a

1 En la reforma que actuamente se está discutiendo en la Cámara de Diputados se encuentran aspectos relacionados con el banco de horas, eliminación del tiempo extra, contratación a prueba y eventuales, además de facilidades para el despido sin indemnización (Barba, 2003:52).

2 Existen muchos autores que consider an el concepto totalmente obsoleto. No obstante, las condiciones - en las cuales se dan las relaciones de producción - confirman la necesidad de ubicar el proceso como una lucha entre capital y trabajo en el ámbito mundial competitivo, que genera constantemente una sobrepoblación relativa. Es atendible la opinión de que ese vocablo resulte demasiado beligerante, por lo que se propone, para evitar rechazos por razones de forma y no de fondo, se le denomine a la sobrepoblación relativa simplemente reserva laboral (RL) [Rendón, 2004:17-18]. Sin embargo, la caracterización que hacemos del mercado de trabajo se acerca más a la definición marxista ejército industrial de reserva.

\section{Desparrollo}


mejorar. Si la inversión decrece, la demanda de obreros y la proporción de la fuerza de trabajo ocupada caen, por ende, se deterioran las condiciones de negociación.

Una modificación en los componentes de la inversión también puede afectar las condiciones de venta de la fuerza de trabajo. Es decir, un cambio en la composición orgánica del capital que aumente los recursos invertidos en medios de producción sobre los constitutivos del capital variable, cambia la relación proporcional y la fuerza de trabajo decrece en la medida que se incrementa el capital total (Marx, 2000:759-808). Por otra parte, el capital antiguo - reproducido con una nueva composición - repele mayor número de obreros que los empleados anteriormente, debido a formas específicas de acumulación. Esta última tiene que enfrentar el cambio estructural de ocupación que se carga más por el lado de servicios y menos hacia industria y agricultura.

De acuerdo con Marx, esta situación produce, de manera constante - y precisamente en proporción a su energía y volumen-, una población obrera relativamente sobrante. En otras palabras, excesiva para las necesidades medias de la valoración del capital y, por tanto, superflua, sin embargo, necesaria para la ampliación de la acumulación capitalista y para regular los movimientos generales del salario. Durante los periodos de estancamiento y prosperidad media, el ejército industrial de reserva —o sobrepoblación relativa- ejerce presión sobre el ejército obrero activo, y pone coto a sus exigencias durante los periodos de sobreproducción y de paroxismo. La sobrepoblación relativa, pues, es el trasfondo sobre el que se mueve la ley de la oferta y la demanda de trabajo.

En este sentido, existen diversas formas de sobrepoblación relativa con distintos matices, no obstante, los obreros la transitan durante el periodo en que están semiocupados o desocupados por completo. Una forma es la fluctuante - cuando a la población trabajadora se le repele o se le atrae nuevamente y en mayor volumen, de tal modo- que en líneas generales, aumenta el número de obreros ocupados, aunque siempre en proporción decreciente con respecto de la escala de producción. La población rural que está en proceso de convertirse en urbana o manufacturera es considerada latente, pues forma parte del movimiento de grandes grupos poblacionales hacia las ciudades, ya sea en el país o a otras naciones. Por último, se encuentra la población intermitente, la cual está constituida por una parte del ejército obrero activo, con una ocupación absolutamente irregular, y en la que el capital tiene a su disposición una masa extraordinaria de fuerza de trabajo disponible. Sus condiciones de vida se encuentran por debajo del nivel medio normal de la clase obrera y es precisamente eso que imprime a dicha categoría una base amplia para ciertos ramos de la explotación del capital. La caracteriza el máximo de tiempo laboral por el mínimo de salario: es el sedimento más bajo de la sobrepoblación relativa y se aloja, finalmente, en la esfera del pauperismo (personas aptas para el trabajo, huérfanos e hijos de indigentes, personas degradadas, incapacitadas para trabajar, personas mayores, víctimas de la industria o de cualquier otra actividad) [Marx, 2000:759-808]. Esta última es la 
población ocupada que más ha crecido en el mercado de trabajo actual, pues el volumen de la oferta laboral es inevitablemente creciente, debido al efecto del aumento poblacional y al desplazamiento ocasionado por el cambio tecnológico. Estas razones generan una gran masa de desempleados y es una presión muy importante en la relación oferta-demanda, en la cual el precio de la mercancía-trabajo se resuelve inevitablemente en favor del capitalista, puesto que el valor de la fuerza laboral está gobernado por la competencia que impone el ejército industrial de reserva.

\section{El empleo formal e informal y la contradicción con la precariedad ${ }^{3}$}

Desde los años sesenta del siglo xx, por medio del Programa Mundial de Empleo, se empezó a difundir el concepto sector informal en el ámbito internacional; sin embargo, fue a partir de los años setenta cuando finalmente se estableció como un vocablo oficialmente aceptado. Los países desarrollados, mediante programas neoliberales y la ideología neoclásica, fueron imponiendo sus criterios a las economías dependientes y en beneficio de las grandes empresas. El término mercado de trabajo se mueve en una posición dual que incorpora una parte de sí mismo al desarrollo y otra que cuenta con un sector no estructurado, en donde se ubica a los trabajadores que no cuentan con una serie de condiciones de reconocimiento y protección del marco jurídico y reglamentario que los hace muy vulnerables. De ahí deriva sector informal, pues se carece de prestaciones contractuales y aspectos correspondientes a la normatividad laboral. Su acceso a infraestructura y a subvenciones públicas es limitado o inexistente; depende en gran medida de actitudes de las autoridades públicas, así como de estrategias de las grandes empresas formales: su empleo es generalmente muy inestable y sus ingresos son muy bajos e irregulares (OIT, 2002:3).

La dualidad del mercado de trabajo alcanzó popularidad en la década de los setenta y se desarrolló con gran fuerza la concepción de la existencia de dos grandes sectores: uno tradicional y otro moderno, los cuales podían ser impulsados por la acción del Estado; semejantes en algunos puntos a las corrientes regulacionistas y segmentalistas ${ }^{4}$ que plan-

3 La tendencia a la precarización se puede definir como insuficiencia de ingresos o necesidad de laborar jornadas mayores a las normales para percibir ingresos que permitan sobrevivir. Además de sufrir pérdida de garantías de bienestar antes existentes en la negociación contractual como punto de referencia en cuanto a prestaciones, beneficios y garantías adquiridas al momento de ser contratados. Al respecto, Chomsky (1995:99) señala que la población precaria tiene una función reguladora, no obstante, en la situación actual, creada por la globalización del capital en su forma neoliberal, se asemeja al escenario en el cual el tamaño de dicha población ha alcanzado tales dimensiones que pone en peligro la estabilidad del sistema.

4 Esta teoría surgió como una reacción a la teoría de la dependencia (De la Garza, 1993:33). Las nuevas necesidades del capitalismo mundial configuraron un cambio estructural importante en los países desarrollados desde principios de los setenta con la llamada nueva división internacional del trabajo, que implicó una ruptura con el fordismo que había tomado cierta importancia en algunos países en desarrollo.

\section{Desparrollo}


tean la existencia de un sector moderno y otro atrasado o marginado del desarrollo. Se habla de lo informal cuando el sector secundario —o industrial— no es capaz de integrarse en relaciones de empleo estables a la gran masa de mano de obra que busca empleo y de la cual, una gran parte se queda al margen de la economía formal, en el llamado sector informal (urbano) $)^{5}$ [Pries, 2000:525].

Keith Hart creó el concepto a partir de una investigación llevada a cabo en Ghana, en la cual se introduce la noción de oportunidades de ingresos formales e informales para estudiar la ocupación en el medio urbano de dicho país, en particular, entre los estratos de población de menores ingresos y múltiples ocupaciones. Hart distingue entre lo formal y lo informal mediante la identificación del primero con el empleo asalariado y del segundo con el empleo por cuenta propia (Rendón, 2000a:553).

La definición de informalidad nos confirma la vinculación teórica con los cambios en la base productiva, pues la Organización Internacional del Trabajo (огт) señalaba que las actividades en expansión estaban ocupando mano de obra con puestos de trabajo sin una relación laboral sujeta a la legislación habitual y al pago de impuestos, además de no tener protección social o derecho a ciertas prestaciones (por ejemplo, preaviso de despido, compensación por éste, vacaciones anuales o licencia pagada por enfermedad, entre otros) [отт, 2002:16]: eran trabajadores cuyo ingenio logró una forma de empleo (lo que ahora se llama autoempleo), en una unidad de producción que formaban ellos mismos. Se trata de una parte del mercado de trabajo desempleado o subempleado al cual podríamos ubicar como sobrepoblación relativa intermitente.

En América Latina, la oIT también jugó un papel importante en la difusión del vocablo y adquirió una gran presencia mediante el Programa Regional de Empleo para América Latina y el Caribe (PREALC). Gracias a ese organismo se adoptó el término sector informal como marco oficial de interpretación del problema ocupacional existente en las ciudades de los países llamados en vías de desarrollo. Ese programa fue el principal impulsor del concepto con fines no solamente descriptivos, sino incluso analíticos (Salas, 1992:26; Pries, 2000:525) y que tendría una gran influencia en los análisis del mercado de trabajo, a partir de 1975, cuando la Secretaría del Trabajo y Previsión Social —en colaboración con el Programa de las Naciones Unidas para el Desarrollo (PNUD) y la OIT, adoptó esos criterios y realizó el primer estudio acerca del sector en México (INEGI, 2004a:10).

Los análisis elaborados por la parte patronal aceptaron la concepción dual de la economía en dos grandes sectores, el formal e informal y agregaron algunas variables para diferenciarlos uno de otro como las características regulatorias en la evasión o el pago de impuestos, reglamentaciones y prohibiciones, así como corrupción burocrática (CEESP, 1986:16-17]. Señalan que las empresas que aplican estas políticas competitivas adquieren

5 La oIT hizo suyo el concepto y lo difundió ampliamente por medio de sus distintos programas y proyectos acerca de empleo y desempleo en las siguientes décadas (INEGI, 2004:VIII). 
ventaja frente a las formales, sin embargo se desempeñan en condiciones inadecuadas $e$ incumplimiento de la ley laboral — como las actividades que no son registradas por las cuentas nacionales o empresarios que declaran no darle prestaciones sociales a sus trabajadores pese a que cumplen con otros requisitos para ser considerados negocios formales.

Esta forma de entender el mercado de trabajo ha generado un alto grado de confusión e importantes cuestionamientos ${ }^{6}$ debido a sus limitaciones y defectos: oculta o distorsiona los efectos de un sistema económico en el cual coexiste el trabajo asalariado en una relación directa con aquel que no recibe un pago pero, en alguna de sus fases, le es necesario al proceso de acumulación. En este sentido, el término sector informal debe tomarse con mucho cuidado, puesto que no permite explicar los orígenes de los problemas ocupacionales de una parte creciente de la población — que está siendo despojada de elementos normativos entre el capital y el trabajo- y deja a los mercados su solución.

De manera más extensa, el concepto supone una relación jerárquica —objetiva y subjetiva - entre los sectores formal e informal. La jerarquía objetiva se refiere a las condiciones generales del trabajo y de vida. Según esta concepción, en el sector formal se encuentran relaciones contractuales estables, salarios relativamente altos, seguridad social, estabilidad en el empleo y buenas condiciones de trabajo. En cambio, el informal está caracterizado por circunstancias laborales precarias, empleos o trabajos inestables, ingresos relativamente bajos, y falta de seguridad social y legalidad de las actividades económicas (Pries, 2000:525). Desde esta perspectiva, sería lógico suponer que una de las aspiraciones fundamentales de los trabajadores informales estaría centrada en su incorporación a la economía formal. Es decir, explotación, desempleo y empleo en condiciones precarias se reducirían a simple problema de voluntades entre empresario y trabajadores para incorporarlos en una actividad cuyo respeto a sus derechos será garantizado. Esta posición conduce a una idea equivocada, la cual señala que el problema esencial para los trabajadores es la creación de empleos y la búsqueda del respeto de sus derechos por medio de la exhortación a la buena voluntad del contratante para que procure el cumplimiento de la legislación del trabajo. Se oculta la lucha entre capital y trabajo por la búsqueda de un empleo en donde la explotación esté incorporada a una normatividad.

Es necesario insistir en que no es nada más problema de voluntades, sino resultado de un enfrentamiento más general entre capital y trabajo por el control o regulación del proceso de valoración y no sólo del simple cumplimiento de la legislación laboral que, por

6 La propia olt ha señalado que la expresión sector informal se considera cada vez más inadecuada e incluso errónea para reflejar estos aspectos dinámicos, heterogéneos y complejos de algo que en realidad es un fenómeno más que un sector - en el sentido de grupo industrial o actividad económica específicos- . En cambio, sugieren la expresión esconomía informal para hacer refer encia al grupo - cada vez más numeroso y diverso de trabajadores y empresas tanto rurales como urbanas- que opera en eseámbito (OIT, 2002:2). Otra definición más reciente señala que es un sector no estructurado o no organizado (INEGI, 2004a:1).

\section{Desarestrollo}


otro lado, en la práctica se está reformando. Son intereses contrapuestos que detectamos cuando vemos que una proporción creciente de empresas formales utilizan, de una u otra forma, estrategias competitivas violatorias de conquistas laborales para lograr mayor movilidad laboral y adaptarla a necesidades del mercado mediante flexibilidad de la fuerza de trabajo - la cual consiste en eliminación de las normas de protección a los trabajadores, con intención de reducir costos laborales- Tal es el caso de sustitución de contratos colectivos por individuales temporales o cambios en sistemas de seguridad social (Rendón, 2000a:542-543). La propia oIT señala que la creación de empleos informales ha generado: bajos ingresos, inexistencia de contratos laborales, falta de prestaciones sociales, no afiliación a organizaciones laborales, con un uso de tecnología atrasada y empresas muy pequeñas (отт, 2002:38).

Por otro lado, las expectativas de extender derechos laborales a trabajadores informales quitarían factores que propician un incentivo para el desarrollo de este tipo de empleo en empresas pequeñas. Sin embargo, como ya lo señalamos, esta situación es aprovechada por muchas empresas formales para hacerse más competitivas e incrementar sus utilidades. En este sentido, se fomenta la subcontratación y la informalidad sin respetar salarios mínimos, estabilidad en el trabajo, jornada laboral o prestaciones. Es por ello que la expansión de la economía informal ha estado ligada a la capacidad de empresas formales de absorber mano de obra y a su voluntad para hacerlo. En lugar de efectuar la producción con una mano de obra regular — localizada en el mercado de trabajo formal—, cada vez más empresas la descentralizan y organizan el trabajo acorde con la idea de especialización flexible: crean unidades de producción pequeñas, flexibles y especializadas, algunas de las cuales no se registran o son informales. Dicha especialización es un mecanismo que busca reducir costos para aumentar la competitividad; las empresas operan cada vez más con núcleos pequeños de asalariados bajo términos y condiciones irregulares; los trabajadores no normalizados o atípicos, localizados en lugares de trabajo informal, crecen, y a menudo también los informales, diseminados en diferentes lugares de trabajo. Estas medidas incluyen contratación externa o subcontratación ${ }^{7}$ y abandono de relaciones de empleo regulares hacia relaciones más flexibles e informales [отт, 2002:39].

Por tanto, muchos trabajadores de este tipo de economía, especialmente los empleados por acuerdos de contratación externa y subcontratación, pueden considerarse asalariados encubiertos más que auténticos trabajadores independientes. El caso del empleo a domicilio es un buen ejemplo y nos ayuda a explicar por qué las mujeres que — según la

$7 \quad$ La competitividad y productividad de la mano de obra en estas empresas se basa más en el uso intensivo de esta última, deterioro de los salarios, inestabilidad en el empleo, aumento de la jornada de trabajo - de preferencia sin pago alguno-, contratación temporal o verbal sin prestaciones de ley, a destajo, a domicilio o subcontratación, entre sus formas más precarias y flexibles (Juárez, 2004:2).

\section{Desesarerstollo}


OIT - constituyen la mayoría de quienes trabajan en esa forma, tienen más probabilidades de estar fuera de la cobertura de la legislación laboral vigente que los hombres . Sus empleadores las tratan como si fueran trabajadoras independientes y, por tanto, no contribuyen a su protección social. No obstante, son totalmente dependientes de una única empresa o empleador para la obtención de equipo, materias primas y pedidos de trabajo. Desarrollan sus labores en condiciones de subordinación y dependencia, pero no disfrutan de derechos y protecciones que les corresponden. Su contrato de servicios, ya sea formal o informal, debería ser uno de trabajo. En algunos casos, los empleadores en última instancia resultan ser corporaciones multinacionales (orT, 2002:55).

Todos estos elementos nos muestran cómo la nueva forma de funcionamiento del modelo de acumulación capitalista en su conjunto utiliza fuerza laboral en condiciones de precariedad porque permite reducir costos mediante evasión de múltiples requisitos legales como son: edad, jornadas de trabajo, salario mínimo, prestaciones sociales o laborales, estabilidad en el empleo, sistemas de salud o pensiones. Ello explica por qué se ha extendido esta forma de trabajo y ha provocado todo tipo de abusos, aunado a obstáculos para que los empelados gocen plenamente de sus derechos. Esta situación se traslada al mercado laboral en su conjunto, pues las negociaciones y la lucha por la defensa de sus conquistas laborales se ven amenazadas por el amplio ejército de asalariados dispuesto a desempeñar esas actividades, independendientemente de la precariedad con que sean contratados.

Por esto, cuando se contrastan las condiciones competitivas de empresas informales con formales se observa que, en muchos casos, estas últimas se encuentran en mejores condiciones competitivas porque no pagan impuestos, no contribuyen a la seguridad social de los trabajadores, o evitan otros costos empresariales en que se incurre en la economía formal. Aun así, con frecuencia trabajadores y empresarios informales son objeto de acoso, chantaje y extorsión — practicados por funcionarios corruptos- y tienen que hacer frente a costos prohibitivos y a procedimientos burocráticos muy complejos para establecer y gestionar empresas (огт, 2002:7). Sin embargo, el funcionamiento empresarial en estas circunstancias les ha sido favorable pese a que está lleno de contradicciones: podemos observar un crecimiento sorprendente del empleo en prácticamente todas las actividades económicas.

La propia Organización para la Cooperación y el Desarrollo Económico (OCDE) señala que la economía informal facilita el fraude fiscal de grandes empresas que operan en el país y no es raro que éstas vendan una parte de su producción en la informalidad. ${ }^{8}$ Es decir, el industrial, el comerciante o prestador de servicios formales producen, distribuyen o trabajan en parte o en su totalidad en la informalidad como consecuencia del alto costo de la regulación o de los impuestos.

8 Véase la página electrónica http:// www.jornada.unam.mx/ 1999/ mayo99/ 990506/ movio.html/ 
Es tan importante el empleo en la informalidad (sobre todo en el autoempleo) para el mercado de trabajo y la relación normal entre capital y trabajo en la compraventa que, aparentemente desaparece la relación laboral. Puesto que es una actividad que genera sus propias mercancías para un mercado, pero sin establecer una relación salarial, en ese escenario, desaparecerían quien demanda fuerza de trabajo y quien la ofrece, de tal manera que, cuando un trabajador realiza una actividad propia, no formaría parte de ese mercado. En consecuencia, los trabajadores por cuenta propia o los familiares no remunerados sólo podrían concebirse como parte de un mercado de trabajo si ambos fuesen incluidos como parte del ejército de reserva laboral, la cual es una categoría más amplia que la de desempleo involuntario (Rendón, 2000a:550). Sin embargo, esta concepción podría conducirnos a otro tipo de problemas como el siguiente: se podría considerar a todos estos trabajadores emprendedores capitalistas (microempresarios), dándoles grandes posibilidades para su desarrollo, cuando la realidad es que la producción capitalista hace uso de ese sistema sólo para realizar el ciclo de valoración del capital.

La realidad nos muestra que el funcionamiento actual del mercado de trabajo — como tal-incorpora a todos los empleados en el sistema de reproducción del capital en alguna de las fases de la acumulación necesarias para su valoración mediante relaciones laborales. Por sus condiciones de vida y trabajo, serían trabajadores informales con la realización de actividades en condiciones de flexibilidad laboral, mientras su situación mejora y pueden ser caracterizados como asalariados con un empleo precario, pero con posibilidades futuras de tener mejores circunstancias.

La ampliación del ejército de desempleados — producto de la disminución de la fuerza de trabajo en la actividad económica — fomenta el autoempleo y la ocupación en negocios pequeños con formas de trabajo flexibles, feminizadas, a domicilio, con jornadas de trabajo discontinuas, pérdida de prestaciones sociales, mayores riesgos de accidentes, trabajos físicos pesados, deterioro salarial, inestabilidad laboral y alteración de las organizaciones sindicales. A su vez, éstas han contribuido al desmantelamiento de la planta laboral, deterioro del ingreso y precarización en el consumo de la fuerza de trabajo (Garavito, 2003:203). Todo ello ha propiciado un daño a las condiciones de negociación entre trabajadores y empresarios.

\section{La reestructuración de la economía}

Ante este panorama, los gobiernos de los países en desarrollo, entre ellos el de México, se vieron obligados a ajustar sus economías y políticas en consonancia con los planteamientos neoliberales. ${ }^{9}$

9 Esta ideología considera que la economía debe ser regulada por ella misma, bancos, bufetes de abogados, agencias de rating y en reuniones de jefes de las naciones más ricas y gobernadores de bancos centrales. También, a partir de dicha ideología se inventó el concepto gl obalización. Por respuesta se asegura que está reviviendo en mayor escala el imperialismo, es decir, el predominio de capital financiero internacional sobre el industrial nacional (Saxe-Fernández, 2002:68).

\section{Desesarerstollo}


Éstos pugnan por libertad comercial y alejamiento del Estado de su actividad directa y se pone como ejemplo el éxito económico de la región de Asia Oriental para justificar el fomento de las economías de mercado, con objeto de ser capaces de competir en un mundo globalizado. Asimismo, es muy fuerte la presión para tener acceso a sistemas financieros internacionales propuestos por el Fondo Monetario Internacional (FMI) y el Banco Mundial (Bм), —los cuales, finalmente aprueban los programas de estabilización y ajuste como condición previa para el refinanciamiento de la deuda adquirida- En esos acuerdos se establecen políticas de liberazación de mercados, eliminación de subsidios y esquemas especiales de importación. Se suprimen múltiples trabas que el proteccionismo prevaleciente había fomentado y que provocó poca capacidad para competir en el mercado mundial, falta de integración de cadenas productivas, creciente dependencia tecnológica, bajos niveles de productividad, mercancías caras y de mala calidad. Además del creciente endeudamiento con el exterior y concentración del ingreso cuyo efecto condujo a una industrialización protegida por elevados niveles arancelarios de altos costos que fabricaban productos onerosos que sólo consumirá una parte reducida de la población (Fajnzylber, 1983:98, 103-104).

Para el logro de esos objetivos era necesario transformar la economía basada en la industrialización sustitutiva de importaciones en una orientada a las exportaciones; el cambio de la política proteccionista hacia la apertura comercial, financiera e industrial; un Estado rector e impulsor de la actividad económica, ${ }^{10}$ a uno que fomente la inversión y paulatinamente disminuya su participación centrando su atención sólo en aquellos aspectos que beneficiaran el proceso económico. Si se reduce la intervención del Estado ${ }^{11}$ y es mayor la participación del mercado en la regulación económica, habrá más probabilidades de lograr el desarrollo económico. Por ello se propuso la reestructuración de la economía - con grandes empresas a la cabeza, las cuales demandaron el retiro del Estado en cuanto a inversión productiva y beneficios sociales-, así como una política de estabilización entre salarios y productividad, conocida por los neoclásicos como flexibilidad del trabajo, ${ }^{12}$ para salir de la crisis que tiene su origen, más profundo, en la rigidez de las relaciones

10 Lo anterior implica la disminución - eincluso desaparición, de programas de fomento económicoy la venta, concesión y licitación de activos públicos del país (Juárez, 2004:1).

11 La política neoliberal sostiene quela intervención del Estado distorsiona los precios y crea cuellos de botella y rigideces en la economía; considera que el libre mercado y la reforma estructural conducirán al crecimiento económico, además plantea que la función del Estado en la economía es ofrecer un marco de referencia para facilitar la producción y estimular precios de mercado, tener cautela fiscal, desregulación, privatización y mercados libres (Damián, 2002:30-31).

12 Son formas de organización del trabajo que incorporan sistemas de fabricación que pretenden terminar con males de rutina (en el planteamiento de Coriat). Además de dar respuesta a demandas del mercado que requiere de fuerza laboral disponible permanentementey acor de con las necesidades del justo a tiempo o cero inventarios son aspectos que las empresas programan para la producción de cierto tipo de bienes y contratan personal según sus necesidades. Se mantiene un número reducido de trabajadores de base - con todas las prestaciones- y un grupo - que tiende a crecer

\section{Desparrollo}


sociales dentro de los procesos productivos. Es decir, la reestructuración implicó la difusión de la idea de superioridad del mercado para asignar recursos y premiar a los más eficientes (individualismo) y un Estado con menor injerencia en la actividad económica. Con esto se busca aumentar la productividad y disminuir costos para lograr mayor competitividad en el mercado internacional. No obstante, estos cambios tuvieron que enfrentar la resistencia de los trabajadores.

Se planteó el agotamiento del paradigma basado en la producción del fordismo ${ }^{13}$ taylorismo, ${ }^{14} \mathrm{el}$ cual basaba su estrategia en la producción en masa — para eliminar amplias diferencias en la productividad del trabajo-, el desarrollo tecnológico, la dinámica de los sectores y de la tasa de beneficios. El modelo presentó deficiencias crecientes, las cuales se convertieron en una pesadilla. Se manifestó una falta de cuidado en la producción; aumento de los defectos de fabricación y de desperdicios, ausen-tismo e imposibilidad de rotación del personal, además de la resistencia a entrar en la fábrica, aspectos que era necesario eliminar (Coriat, 2000:129). Estos problemas se resolverían — de acuerdo con los planteamientos neoclásicos_- mediante la aplicación de una estructura del trabajo distinta que tendiera hacia una nueva composición social y técnica de la fuerza laboral por medio de los nuevos caracteres de las tecnologías basadas en el automatismo. De ahí se desprende la exigencia de una fuerza de trabajo ágil que la dote de flexibilidad en las relaciones laborales para abaratar el precio de la mano de obra y aumentar la productividad. Para ello, se impulsó la reforma del marco jurídico (contratación colectiva, legisla-

cada vez más- contratado por horas, a tiempo parcial, así como trabajadores por su cuenta o a domicilio, los cuales carecen de prestaciones. Esta forma se va convirtiendo en prototipo del trabajo actual. Los instrumentos que utilizan son grupos o equipos de trabajo, círculos de control de calidad, control estadístico del proceso de producción y sistema de justo a tiempo. De aquí se deriva el término espe-cialización flexible de la producción, el cual consiste en hacer productos más variados con mayor rapidez y con rotación de tareas semanales o en el transcurso de un día [Sennett, 2000:52-53].

13 Entre 1910 y 1914, la Ford M otor Company de Highland Park se consideraba un glorioso ejemplo de división tecnológica del trabajo. En cierto modo, Ford era un empleador humano, pagaba buenos sueldos según un régimen de cinco dólares diarios e incluía a sus trabajadores en un plan de participación en los beneficios. En la fábrica, las operaciones eran otro asunto. Henry Ford pensaba que las preocupaciones por la calidad de vida laboral eran "puras pamplinas", y que cinco dólares por día eran una retribución bastante atractiva por aburrirse (Sennett, 2000:40). Después de la Segunda Guerra M undial, el sistema de producción de Estados Unidos, Europa Occidental y Japón experimentaron un régimen de acumulación fordista, ampliado por principios tayloristas de organización del trabajo y racionalización en manufacturas. El taylorismo se caracterizó por una estandarización rigurosa de las prácticas laborales y los productos (intensidad del trabajo) y una separación entre el concepto del trabajo (ingeniería y diseño) y su producción, incorporando los métodos más eficientes de producción (administración científica). No se requirió dela participación del trabajador en el proceso de producción y en el mercado laboral (Dussel, 1997:75).

14 El psicólogo industrial Frederick W. Taylor realizó una serie de estudios acerca de la relación tiempo/ movimiento con cronómetro, midiendo en centésimas de segundo el tiempo que se tardaba en colocar un faro o un guardabarros (Sennett, 2000:41). La gestión del tiempo/ movimiento aplicado a

\section{Desesarerstollo}


ción laboral y sistemas de protección social del trabajador, tales como servicios básicos de salud, educación y pensiones). ${ }^{15}$

El sector privado coincide con este planteamiento en el sentido de que las actividades del Estado sólo deberían abarcar aquellas áreas que no fuesen debidamente cubiertas por el primero; que en la competencia entre los dos sectores —en niveles iguales- el público disponga de ventajas y anule cualquier oportunidad de competencia del sector privado. De igual manera, al entrar el Estado en la competencia se perjudican inversiones privadas basadas únicamente en el principio de ganancias-y, finalmente, el gobierno no debe invadir la esfera que, naturalmente, correspondería a la iniciativa privada, pues las fuerzas del mercado determinarían aquellos aspectos de la vida colectiva que en el modelo intervencionista quedaban claramente ubicados bajo la égida del Estado (Reuben-Soto, 1995:26).

La modificación del patrón de acumulación fue coincidente con los procesos de apertura impulsados por los organismos financieros internacionales y trajo implicaciones comerciales, productivas, tecnológicas y financieras para los países en donde se combinaron cuatro elementos: $a$ ) impulso a las exportaciones; ${ }^{16} b$ ) creación de enlaces posteriores y anteriores a fin de desarrollar la industria de bienes de capital; ${ }^{17}$ c) racionalización del proteccionismo, y d) redefinición del papel del Estado [Rivera, 2000: 141-142]. Todas las fallas del patrón de acumulación anterior se atribuyeron a políticas proteccionistas y se tomaron como pretexto para dar paso a nuevos requerimientos de la economía mundial, la cual rechaza los principios fundamentales del proteccionismo: intervención estatal en la economía y protección arancelaria para generar confianza e incentivar al sector privado orientado a las exportaciones, también fueron factor importante en la estabilización de la balanza de pagos. Se busca la refundación económica del país con reducción drástica de protección arancelaria y recuperación, para el mercado, del papel de árbitro supremo de la acción económica (Fajnzylber, 1983:244). Esas propuestas se concretaron en recortes al

la producción es lo que le dio este nombre. Otra definición señala quees el trabajo manual (ejecución) que se separa del trabajo de concepción (intelectual) en el proceso productivo.

15 Véase Carnoy (2001:11) quien agrega que no es el fin del trabajo, sino su diversificación lo que caracteriza el nuevo mundo tecnoeconómico. Se sustituyela socialización laboral por la especialización productiva en un sistema inestable de subcontratación; prestaciones de servicios limitadas en tiempo y espacio, trabajo de información; intercambio y redefinición constante de las relaciones de cooperación y competencia. En estas condiciones, la temporalidad se fragmenta, la homogeneidad de las condiciones laborales desaparece y, por tanto, la suma de intereses se produce en torno a proyectos y no a partir de la comunidad de condiciones de vida y de trabajo.

16 Este planteamiento señala que se podría conceptualizar el proyecto de liberalización iniciado en 1982 dentro del marco de la "industrialización orientada hacia las exportaciones". La estrategia gubernamental mexicana se basó en varios mecanismos de mercado: reducción de las actividades económicas y sociales del gobierno y de su déficit fiscal, eliminación de mecanismos de proteccionismo comercial, considerando al sector privado pilar del crecimiento nacional y la subsiguiente privatización masiva de empresas paraestatales. Además, la garantía de fuerza de trabajo barata constituyó un elemento crucial dentro de esta estrategia (Dussel, 1995:136).

17 Algunos autores manejan el término ingeniería de reversa, el cual consiste en la desagregación de paquetes, productos y procesos tecnológicos a fin de comprender y asimilar su composición,

\section{Desaarsollo}


gasto público, privatización de empresas paraestatales, ajustes en el tipo de cambio, y reorientación del esquema generalizado de subsidios para promover actividades manufactureras orientadas a la exportación; además de garantizar una fuerza de trabajo barata, la cual se constituye en elemento esencial para la estrategia neoliberal que provocaría modificación de procesos productivos, organización del trabajo y relaciones laborales. ${ }^{18}$

El patrón de acumulación que se va imponiendo se identifica con la teoría económica neoclásica mediante conceptos llamados toyotismo, ${ }^{19}$ especialización flexible ${ }^{20} \mathrm{o}$ neofordismo. Éstos, se entienden fundamentalmente como eliminación de obstáculos, con el objeto de que mecanismos del mercado de manera espontánea se encarguen de asignar precios y empleo al factor trabajo (De la Garza, 1998:93). Esos cambios implicaron profundas modificaciones en relaciones laborales y la forma de organización del trabajo por medio de: círculos de calidad total, ${ }^{21}$ equipos y células de trabajo, cero errores, control estadístico del proceso, justo a tiempo y cero inventarios, control de calidad total, control integral de procesos y manufactura flexible. Además de vinculación con la estabilidad en el empleo, polivalencia, ${ }^{22}$ pagos por antigüedad, en contraposición con el desempeño de funciones específicas, y pago de compensaciones a los trabajadores de acuerdo con su calificación y la rentabilidad de la empresa.

El empleo adquiere una connotación diferente por el nuevo papel que juega ante estas profundas transformaciones, las cuales incluyen un alto grado de control del proceso de trabajo, y hacen necesario un sistema político autoritario y sindicatos controlados que permitan la creciente desregulación del mercado laboral. Es decir, estos procesos tuvieron un impacto significativo en el mundo del trabajo, tanto en lo que se refiere al mercado laboral, como a las instituciones y organizaciones que intervienen.

Las relaciones de trabajo mediante la subcontratación ${ }^{23}$ fueron uno de los cambios más sensibles que tomó gran relevancia entre los empresarios en general, pues permitió reducir

funcionamiento, diseño y aplicación, para luego reproducirlos, e incluso mejorarlos localmente (Saxe-Fernández, 2002:514).

18 La estrategia de ajuste impuesta se consolidó mediante varios pactos económicos establecidos desde 1987 que, principalmente, persiguieron el control dela inflación y del déficit fiscal mediante ajuste de salarios reales y del tipo de cambio, de aceleración de la liberalización comercial desde 1985 y reducción de impuestos a varios productos de consumo básico (Dussel, 1995:137).

19 La flexibilidad polivalente del toyotismo es, sobre todo, interna, entre puestos, categorías, departamentos, turnos o de horario de trabajo; también en criterios de ascenso de acuerdo con la capacidad y no por antigüedad, y salarial (en función del desempeño) [De la Garza, 1998:96].

20 El mismo autor señala que es otra de las corrientes importantes del posfordismo, el cual también plantea que la producción en masa llegó a su límite y coincide con la emergencia del nuevo paradigma tecnológico en un contexto de predominio de una economía de variedad (clientes que la exigen junto con la calidad en los productos) [De la Garza, 1998:96].

21 Son las organizaciones de todo el personal de la empresa - desde el gerente hasta el obrero- para que los productos o servicios no tengan ningún defecto de fabricación.

22 El trabajador multifuncional o polivalente realiza diferentes actividades, lo cual propicia que desaparezca un buen número de categorías laborales que antes se manejaban en la contratación colectiva.

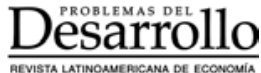


costos laborales y aumentar la calidad de los productos. Es otras palabras, se busca no sólo eliminar los obstáculos para el uso de la fuerza laboral, sino crear una relación diferente entre trabajadores y supervisores en el proceso de producción, con capacidad de cambiar a voluntad el número de empleados, su desempeño de acuerdo con las necesidades de la empresa, sin restricciones, con ajuste de sus salarios a la productividad y según la jornada de trabajo.

\section{Las tendencias del empleo y la informalidad}

El elevado ritmo de crecimiento de la población económicamente activa (PEA) que se incorpora al mercado, el nivel de desarrollo tecnológico y el limitado crecimiento económico imposibilitan que buena parte de los trabajadores encuentre opciones de empleo formal, tanto que, una proporción creciente, tiene que desempeñar alguna otra actividad para obtener un ingreso pese a que esas alternativas sean precarias, ${ }^{24}$ informales, ${ }^{25} \mathrm{o}$ bien, tenga que emigrar ${ }^{26} \mathrm{o}$ incorporarse a la industria maquiladora de exportación (receptora importante de trabajadores), ${ }^{27}$ todo ello sin contar a aquellos que engrosan las filas de desempleo. ${ }^{28}$

23 Empresas contratadas ex profeso elaboran parte del producto o realizan al guno de los servicios que requieren las plantas, como limpieza, mensajería y cobranza. La volatilidad de los mercados da ventaja a la producción en pequeños lotes flexibles al gusto del consumidor; dicha flexibilidad del producto y del proceso se compagina con tecnología reprogramable, reevaluación de las calificaciones y participación de los trabajadores en procesos productivos con mayor autonomía, iniciativa y creatividad (De la Garza, 1993:23). De esta forma, el desglose de esta actividad muestra cómo el empleador se libera de toda relación con esos trabajadores, los cuales evitan que se haga cargo de molestas revisiones contractuales y salariales, pagos al seguro social o prestaciones que en algún momento había acordado con sus trabajadores.

24 En una economía en la cual los ahorros de los trabajadores son prácticamente cero, y en la cual, además, el gobierno no proporciona ningún tipo de ayuda a los desempleados, sólo un número reducido de trabajadores puede darse el lujo de permanecer desempleado por mucho tiempo. Por tanto, quienes perdieron su empleo se ven forzados a aceptar uno disponible, sin importar salario, condiciones de trabajo o compatibilidad con su entrenamiento y habilidades (Salas, 2003:57).

25 Los trabajadores que se emplean en la economía informal no cuentan con seguridad social ni con prestaciones de ley y en su gran mayoría reciben ingresos marginales. No obstante, millones han encontrado en la economía informal una de las más importantes válvulas de escape para subsistir al deterioro salarial y a su condición de desempleados. Sin embargo, esta opción no cambia su pobreza y marginalidad, sólo les permite sobrevivir ( Juárez, 2004:15).

26 Según datos del Consejo Nacional de Población (CONAPO), las personas productivas que emigran a Estados Unidos incrementaron de 28 mil al año en la década de los sesenta, a 138 mil y 235 mil anuales en los ochenta y noventa, respectivamente, y para el periodo 2000-2002 la cifra alcanzó 309 mil mexicanos al año (Juárez, 2004:16). Es decir, al rededor de la ter cera parte de los trabajadores que se incorpora al mercado de trabajo sólo tiene como opción abandonar el país para encontrar un empleo.

27 Esta actividad tuvo un crecimiento explosivo en la década de los noventa, sobre todo a partir de 1996. En 1999 ocupó un promedio de 1131316 personas, representando 27\% del empleo en unidades fijas del sector manufacturero (Rendón, 2000b:64). En los últimos años se han observado grandes fluctuaciones debido a la recesión económica internacional, sin embargo, sigue representando un porcentaje muy importante del empleo total.

28 El índice de desempleo abierto pasó de $3.7 \%$ en 1994 a $6.2 \%$ con la crisis de 1995. A partir deese año se observó una disminución sensible hasta alcanzar $2.2 \%$ en 2000 , situación que se revirtió al

\section{Desparrollo}


En todas las formas que adquiere el mercado de trabajo está la presencia del Estado, el cual orienta su acción al apoyo de intereses capitalistas. Por ejemplo, permite que haya espacios de ilegalidad susceptibles de ser explotados por la vía de remuneraciones arbitrarias; desprotección del trabajador; ausencia de prestaciones y, en general, se carezca de vigilancia en las relaciones obrero-patronales. Además se utilizan estas condiciones para presionar al conjunto de empleados a mantener salarios a la baja y se fomente el deterioro de las circusntancias laborales. Es claro que si todos los trabajadores tuvieran empleo, las posibilidades de negociación de sus condiciones laborales les serían distintas y favorables. Pero si, por el contrario, las huelgas se ven amenazadas por la contratación de quienes o no tienen trabajo o tienen uno precario, sin estabilidad y con bajísimos salarios; entonces los capitalistas tienen una ventaja más de su lado (Valle, 2004:2). En estas condiciones se impone un control muy estricto de la fuerza de trabajo y se establecen relaciones laborales con beneficios para el capital.

\section{El desempleo y la informalidad en el mundo}

Para poder entender la situación del mercado de trabajo en el ámbito nacional es necesario, entonces, tener idea del comportamiento de la ocupación en el nivel mundial que responde a condiciones internacionales de la reproducción capitalista y de problemas cíclicos recurrentes de la crisis económica. Como ya lo señalamos, para resolver el problema del desempleo, la posición neoclásica planteó el abandono de las políticas keynesianas de desarrollo industrial que se habían establecido con el modelo sustitutivo de importaciones. Se propone un modelo de crecimiento hacia afuera, que implicaba atender los aspectos macroeconómicos y abandonar políticas esenciales del antiguo modelo para incorporarse exitosamente en la globalización, por medio de las exportaciones.

El nuevo patrón de acumulación capitalista propició la reestructuración del mercado de trabajo en el contexto de la globalización al cambiar la participación del Estado en el fomento del empleo (prioridad en el modelo anterior) debido al ajuste que genera el mercado. ${ }^{29}$

La explotación capitalista va incorporando más trabajadores; este proceso se intensifica por el deterioro de los salarios reales y porque cada vez es más difícil que las familias puedan vivir del ingreso de uno solo de sus integrantes. Así, un número creciente de mujeres, que antes desempeñaba otra función en la reproducción de la familia, ahora tiene que combinar quehaceres domésticos con un empleo asalariado o por cuenta propia, así sea de tiempo parcial..$^{30}$ La situación amplió de manera significativa la oferta de trabajo en

registrar, a partir de ese año, un incremento constante del desempleo abierto de $2.4 \%$ en 2001 , $2.7 \%$ en 2002 , 3.3\% en el 2003 y $3.6 \%$ en 2004 (INEGI, 2003).

29 Se reemplazan empleos estables de tiempo completo por otros temporal es o a tiempo parcial, mientras que se aplican políticas de restricción y dispersión salarial con una disminución de los salarios reales y un número cada vez mayor de trabajadores que sólo tiene acceso a puestos de trabajo de salario bajo 0 de baja productividad (Rendón, 2004:80).

\section{Desesarerstollo}


Cuadro 1

El desempleo en el mundo en 1993, 1998 y 2000-2003 (en millones)

\begin{tabular}{lcccccc}
\hline \multicolumn{1}{c}{ Año } & 1993 & 1998 & 2000 & 2001 & 2002 & 2003 \\
\hline Total & 140.5 & 170.4 & 174 & 176.9 & 185.4 & 185.9 \\
\hline Hombres & 82.3 & 98.5 & 100.6 & 102.7 & 107.5 & 108.1 \\
Mujeres & 58.2 & 71.9 & 73.4 & 74.3 & 77.9 & 77.8 \\
Jóvenes, total & 69.5 & 79.3 & 82 & 82.9 & 86.5 & 88.2 \\
Jóvenes, hombres* & 41.2 & 46.9 & 48.5 & 49.1 & 51.3 & 52.4 \\
Jóvenes, mujeres* & 28.3 & 32.4 & 33.5 & 33.8 & 35.2 & 35.8 \\
\hline
\end{tabular}

Fuente: огт, Tendencias mundiales del empleo 2004.

el mercado mundial y con ello estableció la posibilidad de emprender la reestructuración económica en ese ámbito, con un comportamiento del desempleo a la alza, en prácticamente, todas las regiones del mundo, particularmente para los jóvenes. Este hecho instrumentó condiciones para dar impulso al empleo informal en el mercado de trabajo y la tendencia a desplazar fuerza laboral de la formalidad hacia empleos precarios en todas las actividades.

El cambio estructural del mercado de trabajo generó un número creciente de desempleados en el mundo. En 1993 se registraron 140.5 millones de personas sin empleo, esta cifra se incrementó a 185.9 millones en 2003 (véase el Cuadro 1). Es importante destacar que esta sobrepoblación relativa o ejército de reserva representa un grave problema para todos los trabajadores del mundo, pues tan sólo en la última década del siglo xx y en los primeros años del XxI, la población que se incorporó a dicho ejército fue de 45.4 millones de personas, lo que representa una cifra superior al total de la fuerza de trabajo ocupada en México.

Una característica esencial de la movilidad de los capitales es la búsqueda de utilidades, así pues, se desplazan hacia aquellos sectores o ámbitos en los cuales obtienen mayores beneficios. Un elemento fundamental de este proceso se dio mediante bajos salarios y deterioro de relaciones laborales; de este modo, se articula una enorme red, compuesta por diversas variantes productivas, contrataciones de todo tipo y trabajadores que, en condiciones de flexibilidad total o parcial lograda por la reestructuración, sostienen la cadena de producción y comercialización mundial. Buscan fuerza de trabajo barata, políticamente dócil, con baja protección estatal y de fácil acceso local y regional (Alarcón, 2002:95).

El crecimiento del desempleo ${ }^{31}$ en el ámbito mundial permite el establecimiento de esas condiciones, por consiguiente, los nuevos trabajadores tienen como única opción

30 La incorporación de mujeres a la producción social - ocurrida durante la Segunda Guerra M undial en los países beliger antes- continuó después de la contienda y se hizo extensiva a otras regiones del mundo. Hasta el inicio de los años sesenta tal fenómeno se explica fácilmente por el auge inusitado que registró la economía mundial en ese entonces, lo cual dio lugar a un crecimiento continuo de fuentes de trabajo (Rendón, 2004:59).

31 La oIT señaló que para absorber los candidatos al mercado de trabajo mundial será necesario crear unos 500 millones de empleos durante la presente década. Pero si prevalece la tendencia en la informalidad, esos empleos no contribuirán a aliviar la pobreza y no harán más que aumentar las

\section{Desarestrollo}


incorporarse a empleos precarios. El aumento del empleo informal, especialmente en los países que carecen de sistemas de seguro de desempleo amplios, como es el caso de México, incrementó niveles de pobreza ${ }^{32}$ (огт, 2003:1). No es extraño que haya sido en estas circunstancias en las cuales se creó mayor número de empleos en los últimos años. Es un dilema porque, a pesar de que trabajadores informales adolecen de graves carencias en términos de sus derechos laborales, condiciones de trabajo inadecuadas, falta de protección jurídica y social, e inexistencia de representación y participación, tienen que aceptarlas. ${ }^{33}$ Los flujos migratorios en el nivel mundial tienen que ver con el desplazamiento campo-ciudad, producto del desarrollo capitalista, para ser ocupados en el ámbito industrial, servicios, o incorporarlos al ejército de desempleados, en el cual prevalecen las formas de ocupación informal. La composición social y las oportunidades de integración de emigrantes varían con el tiempo y según los lugares de origen. Las condiciones de empleo y de remuneración son tan heterogéneas que no están adecuadamente reflejadas en el tratamiento que se ha hecho de marginalidad (Pries, 2000:530).

Es tan relevante el empleo informal en el mercado mundial de trabajo que la propia oIT llegó a la conclusión de que el término sector informal debiera corregirse en el contexto de la economía informal, al considerar que ya no era un fenómeno temporal o marginal pues la mayor parte de los nuevos empleos generados en los últimos años, particularmente en los países en desarrollo y en transición, se crearon en dicha economía. Concluye que la mayoría de las personas ha pasado a la economía informal porque no podía encontrar un empleo o emprender una actividad empresarial en la economía formal (orT, 2002:1). ${ }^{34}$

\section{El desempleo y la informalidad en México}

La situación nacional de la fuerza de trabajo está igualmente vinculada al crecimiento acentuado de la población económicamente activa (PEA) ${ }^{35}$ derivada de la dinámica de-

filas de los trabajadores pobres. Es necesario un crecimiento económico a corto plazo y políticas para promover la creación de oportunidades de trabajo decentes y productivas (0IT, 2003:1).

32 En 2003 la olT calculaba en más de 550 millones el número de trabajadores que sobrevive con un dólar (o menos) al día (oIT, 2003:1).

33 Un ejemplo de esto es la tendencia que registra la protección social, pues sólo $20 \%$ de los trabajadores de todo el mundo disfrutaba de esa protección, mientras que más de la mitad de los trabajadores del mundo y sus familias estaban excluidos de todo tipo de ben eficios de la seguridad social formal. No estaban amparados ni por un régimen de seguro social contributivo ni por un sistema de asistencia social financiado con impuestos (oIT, 2002:62-63).

34 Rendón y Salas señalan que, en sentido estricto, la idea de mercado supone un acto de compraventa de una mercancía. Así, la noción de mercado laboral implica el acto de venta de la mercancía fuerza de trabajo y su compra. Por esta razón el mercado laboral está formado sólo por patrones y trabajadores asalariados (Rendón, 2000a:549).

35 Está formada por todos aquellos individuos en edad de trabajar que realizan alguna actividad económica remunerada y los que buscan trabajo activa e ininterrumpidamente durante la semana anterior a la encuesta del estudio muestral (INEGI, 2003). 
mográfica, aumento de la participación de las mujeres ${ }^{36}$ en el mercado laboral, desarrollo tecnológico y niveles de crecimiento económico. ${ }^{37}$ Lo anterior le da cierta orientación a problemas del desempleo y a un proceso ascendente del empleo informal semejante a lo analizado para el ámbito mundial.

El Estado hizo a un lado la forma tradicional de generación de empleos, con ello, dio un viraje drástico al patrón de acumulación como respuesta a las recurrentes crisis económicas que estrechó los márgenes de relación laboral entre gobierno y sindicatos, los convirtió en un instrumento de control de la inconformidad frente a los retrocesos en las condiciones de vida y de trabajo. Además los despojó de su papel en la gestión de reivindicaciones obreras, pese a que en los años noventa, al igual que en la década anterior, el empleo continuó creciendo a mayor ritmo que la producción y que la población en edad laboral. En este decenio, tanto quienes trabajan de manera autónoma, como quienes perciben salario, vieron mermados sus ingresos reales, a la par que la dispersión de los ingresos laborales se incrementó, lo mismo que la fuerza de trabajo remunerada (Rendón, 2004:130, 135). ${ }^{38}$

Nuestro país requiere la generación de un millón 100 mil plazas nuevas anualmente: ${ }^{39}$ en el lento crecimiento de la economía, la creación de empleos es uno de los problemas más graves. Ante la imposibilidad de que trabajadores permanezcan desempleados, se tienen que incorporar a actividades formales precarias o informales que representan un porcentaje creciente de la fuerza laboral ocupada. En este panorama se reorganiza el trabajo en torno a una gestión centralizada, a la diferenciación del trabajo y la personalización de los productos, de ese modo, se individualizan las tareas laborales y diferencia a los trabajadores respecto de supervisores y empresarios. Esto ha simplificado mucho la subcontratación,

36 El porcentaje de mujeres activas respecto de las que están en edad de trabajar pasó de 31.5\% en 1991 a 36.8\% a finales del siglo (M anzo, 2000:51).

37 La composición del empleo también presenta cambios estructurales significativos en el ámbito de grandes divisiones. Se presenta una creciente y continua terciarización de la economía mexicana desde 1970, particularmente desde 1982. De tal manera, la participación porcentual de la agricultura, minería y manufactura disminuyeron significativamente, mientras que aumenta para el sector servicios (Dussel, 1995:137). Según Ios datos más recientes de INEGI, si se considera a la población ocupada por sector económico en el que laboran, se tiene que 6.8 millones (que representa $16.3 \%$ del total) están en el sector primario; 10.4 millones (24.9\%) en el secundario o industrial y 24.3 millones (58.4) trabajan en el terciario o de los servicios; el restante $0.4 \%$, para los que no especificaron su actividad económica (INEGI, 2004a:3).

38 En el ámbito nacional destaca el enorme peso de los sectores comercio y servicios en el empleo total. Las actividades terciarias cubren $57 \%$ del empleo total. Es en estas actividades en las cuales se concentra una absoluta mayoría de mujeres ocupadas; esto refleja la división del trabajo por género, que caracteriza la economía mexicana (Rendón, 2000b:57).

39 La oIt llama la atención respecto de los retos que tiene M éxico en materia de empleo a principios del siglo XXI y señala que en los próximos diez años se espera la incorporación de aproximadamente 11.4 millones de personas al mercado laboral, es decir, un millón 140 mil personas en promedio anual. El organismo afirma que para dar trabajo a nuevos demandantes, la economía tendría que crecer alrededor de 7\% anual ( Juárez, 2004:13).

\section{Desparrollo}


el empleo a tiempo parcial y la contratación laboral eventual, puesto que gran parte del trabajo puede reducirse a tareas específicas, del mismo modo que otro tipo de empleo, el trabajo básico, se desarrolla en equipos y una organización multitarea (Carnoy, 2001:22-23, 34).

El hecho de que el trabajo constituya la fuente primordial de ingresos de la mayoría de las familias mexicanas - incluso sin seguro de desempleo- hace que los problemas ocupacionales de México se manifiesten con mayor gravedad la tasa de desempleo abierto, en la precarización del empleo asalariado y no asalariado y en un número creciente de proveedores de ingreso por familia. La proliferación de actividades de muy pequeña escala, el incremento de trabajo familiar sin pago y del trabajo asalariado a destajo, así como el aumento de la población trabajadora sin acceso a prestaciones, son muestras claras de la merma sufrida en la calidad de los empleos. Otra expresión de precariedad radica en la duración de la jornada de trabajo, la disminución de los salarios y la flexibilización del mercado laboral (Rendón, 2004:135-136).

Por otro lado, el empleo informal o precario no es un fenómeno nuevo, sin embargo, en los últimos años ha adquirido gran relevancia debido a que su crecimiento está asociado al crecimiento de la población, al raquítico crecimiento de la economía, a los cambios estructurales impulsados por la innovación tecnológica. De esa forma, se intensifica la escasez de fuentes de trabajo y se obliga al conjunto de trabajadores a la realización de actividades con características de precariedad, o bien, se les orilla a la búsqueda de empleo fuera de las fronteras nacionales. Es decir, la conformación del mercado de trabajo sigue respondiendo a las leyes de la acumulación. Por un lado están los ocupados formales con sus prestaciones y logros laborales; por otro, los despedidos por la crisis o innovaciones tecnológicas que conforman los desempleados y, por último, la incorporación de nueva fuerza laboral que en conjunto con los anteriores constituyen la fuerza de trabajo disponible. Una parte de esa población no encuentra ocupación en la formalidad y tiene que aceptar empleos precarios, informales o emigrar. Cualquiera de las posiciones que tome la fuerza laboral en ese mercado sigue respondiendo a las necesidades de la valoración capitalista tanto en industria, comercio o servicios.

Un ámbito de negociación entre capital y trabajo ha sido el bajo precio que adquiere la fuerza laboral en las condiciones antes descritas, así pues, el deterioro del poder adquisitivo del salario es un indicador importante de la precariedad laboral que se intensificó a mediados de los setenta y, con algunos altibajos, se prolongó hasta nuestros días para el conjunto de los asalariados. En el Cuadro 2 podemos ver un ejemplo de la evolución del salario real para los trabajadores que perciben el salario mínimo. Éste, de acuerdo con los datos de la última década, registra una proporción importante de la fuerza de trabajo ocupada con niveles de ingresos inferiores a un salario mínimo (6.2 millones de trabajadores) y los que percibían entre uno y dos salarios mínimos (más de 9 millones de asalariados); es decir, casi la mitad de la población trabajadora tenía un ingreso entre uno y dos 
Cuadro 2

Población por nivel de ingreso

\begin{tabular}{|c|c|c|c|c|c|c|c|}
\hline Condición & 1993 & 1995 & 1996 & $1998 *$ & $2000 *$ & $2002 *$ & $2003 *$ \\
\hline $\begin{array}{l}\text { Nivel } \\
\text { de ingreso }\end{array}$ & 32584838 & 33578414 & 35005893 & 38401102 & 39300550 & 40117122 & 40469046 \\
\hline $\begin{array}{l}\text { Menos } \\
\text { de } 1 \text { salario } \\
\text { mínimo }\end{array}$ & 6186938 & 6401483 & 6811516 & 7407204 & 6286435 & 6288995 & 6213516 \\
\hline $\begin{array}{l}\text { De } 1 \\
\text { hasta } 2 \\
\text { salarios } \\
\text { mínimos }\end{array}$ & 9281366 & 10402555 & 11027716 & 11776415 & 11225173 & 9773205 & 9950403 \\
\hline $\begin{array}{l}\text { Más de } \\
2 \text { hasta } 5 \\
\text { salarios } \\
\text { mínimos }\end{array}$ & 8738757 & 8027294 & 8400092 & 9696425 & 12435414 & 14766933 & 15273344 \\
\hline $\begin{array}{l}\text { Más de } \\
5 \text { salarios } \\
\text { mínimos }\end{array}$ & 2251224 & 2373165 & 2425957 & 3074896 & 4040694 & 4321514 & 4229345 \\
\hline $\begin{array}{l}\text { No recibe } \\
\text { ingresos }\end{array}$ & 4517847 & 5122752 & 5119063 & 5056751 & 4157923 & 3648938 & 3442676 \\
\hline $\begin{array}{l}\text { No } \\
\text { especificado }\end{array}$ & o 1608706 & 1251165 & 1221549 & 1389411 & 1154911 & 1317537 & 1359762 \\
\hline
\end{tabular}

* Excluye a los iniciadores de un próximo trabajo.

Fuente: 1993-1996: Encuesta Nacional de Empleo 1999, INEGI-STPS, 2000.

1998-2003: Encuesta Nacional de Empleo 2003, INEGI-STPS, 2003.

http://www.stps.gob.mx/01_oficina/05_cgpeet/302_0058.htm

salarios mínimos, lo cual coloca a la mayor parte de la población en niveles de subsistencia muy cercanos a la pobreza extrema. Además de que una parte significativa de estos trabajadores eran informales con empleo precario.

En los últimos años, la tendencia señala un freno a la pérdida del poder adquisitivo de los asalariados con ingresos mínimos y, según la información oficial, una recuperación más clara para los salarios contractuales, aunque para ambos casos, el repunte es tan pequeño, con respecto de la caída del salario real en el largo plazo, que resulta poco significativo (véanse el Cuadro 3 y la Gráfica 1).

En términos nominales, el salario mínimo promedio de la República Mexicana pasó de $\$ 13.97$ diarios en 1994 a $\$ 6.42$ en 1995, \$35.12 en 2000 y \$41.53 en 2003 ante una inflación de $7 \%$ para el primero, $52 \%$ en la crisis, $9 \%$ en 2000 y $3.8 \%$ en el último año, situación que manifiesta el deterioro de $23 \%$ en el salario real y una tenue recuperación en los últimos años que da una pérdida acumulada del $20 \%$ para toda la década.

Uno de los factores que explica el deterioro salarial es el incremento del desempleo en nuestro país ante la situación de bajo nivel de crecimiento económico e incluso tasas

\section{Desararrollo}


Cuadro 3

Salario mínimo real promedio de Estados Unidos Mexicanos, ${ }^{a}$ 1994-2003

\begin{tabular}{lcccc}
\hline Periodo & Pesos & $\begin{array}{c}\text { INPC }{ }^{\mathrm{b}} \text { diciembre de } \\
\text { cada año }\end{array}$ & $\begin{array}{c}\text { Índice de precios } \\
(1994=100)\end{array}$ & $\begin{array}{c}\text { Salario } \\
\text { real pesos }\end{array}$ \\
\hline 1994 & 13.97 & 7.1 & 100.00 & 13.97 \\
1995 & 16.42 & 52.0 & 152.00 & 10.80 \\
1996 & 20.39 & 27.7 & 194.10 & 10.50 \\
1997 & 24.30 & 15.7 & 224.57 & 10.82 \\
1998 & 28.30 & 18.6 & 266.34 & 10.63 \\
1999 & 31.91 & 12.3 & 299.11 & 10.67 \\
2000 & 35.12 & 9.0 & 326.03 & 10.77 \\
2001 & 37.57 & 4.4 & 340.37 & 11.04 \\
2002 & 39.74 & 5.7 & 359.77 & 11.05 \\
2003 & 41.53 & 3.8 & 373.44 & 11.12 \\
\hline
\end{tabular}

a Ponderado con la población asalariada total de cada zona, estimada sobre la base de datos censales.

b Índice Nacional de Precios al Consumidor.

Fuente: elaboración propia con base en Comisión Nacional de Salarios Mínimos, http://www.stps.gob.mx/ index2.htm

Gráfica 1. Salario real, 1994-2003.

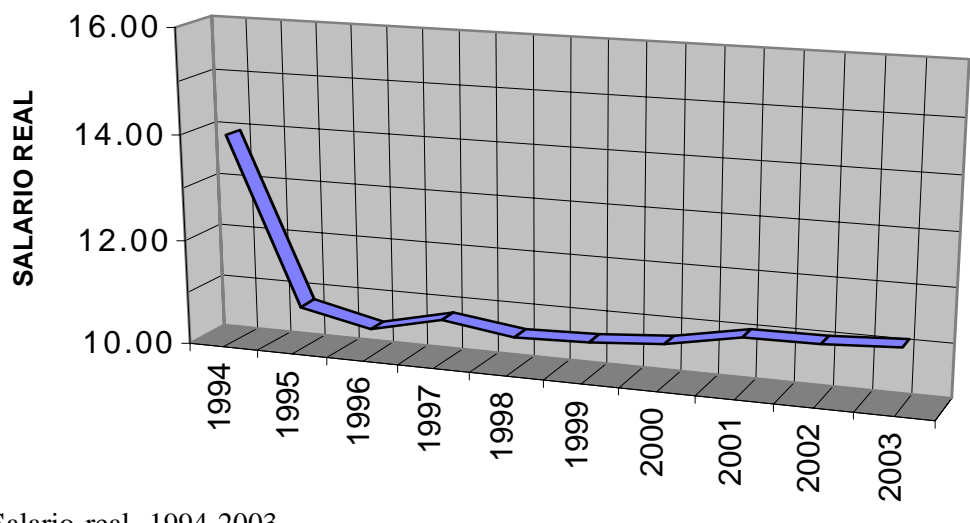

Fuente: Cuadro 3. 
negativas en algunos periodos. Como consecuencia de ello, hay una reducida creación de empleo formal y los incrementos de la PEA se ven desplazados de forma creciente hacia la informalidad y los mercados externos sobre todo por la creciente incorporación al mercado laboral de jóvenes que, junto con el desempleo creciente, deterioraron la calidad del trabajo. La utilización de mecanismos como la subcontratación de pequeños talleres y de trabajo a domicilio por parte de las grandes empresas, la permanencia del pequeño comercio tradicional y la proliferación de pequeños establecimientos dedicados a la preparación de alimentos, fueron posibles debido a condiciones existentes (Chavarín, 1999:42).

En 1993, la Encuesta Nacional de Empleo elaborada por el Instituto Nacional de Estadística, Geografía e Informática (INEGI), registró una PEA ocupada de 32.8 millones; el número de trabajadores que la conformaban once años después fue de 42.3 millones de personas (véase Cuadro 4). De acuerdo con la misma institución, 15.4 millones (37.3\%) recibieron algún tipo de prestación por su trabajo, ya sea en materia de seguridad social, reparto de utilidades, aguinaldo, vacaciones, entre otras (INEGI, 2004b:4), en tanto que el resto no tenía ninguno de dichos beneficios. Es decir, el número de ocupados en México se incrementó a 9.5 millones de personas en una década. No obstante, la mayoría fue contratado fuera del sistema legal o formal, de este modo podemos señalar que el mercado de trabajo ha seguido creciendo de manera muy importante. Las características de precariedad son cada vez más preocupantes, ya que de la PEA ocupada, menos de la mitad tiene un empleo con las condiciones formales definidas anteriormente.

El Cuadro 5 muestra a la población trabajadora registrada en el IMSS y el ISSSTE, incluye a los permanentes y eventuales que cuentan con la seguridad social, por lo que se les puede caracterizar como empleos formales. En 1994, eran 13.7 millones los trabajadores contratados en este régimen y la cifra se incrementó a 17.7 millones en los primeros dos años del nuevo milenio, lo cual representó un aumento de 4 millones en ocho años, cuando el mercado de trabajo creció al doble. Es decir, proporcionalmente se reduce cada vez más la población ocupada que cuenta con seguridad social.

Lo anterior significa que $67 \%$ de la población ocupada no cuenta con seguridad social, aunque se pueden registrar también porcentajes muy parecidos en cuanto al incumplimiento de las prestaciones de ley al no recibir aguinaldo, vacaciones pagadas, prima vacacional, créditos de vivienda, percepción de utilidades (Juárez, 2004:4, 8-9). En este sentido, en los últimos años, la mayoría de los trabajadores mexicanos que se han incorporado al mercado de trabajo, ${ }^{40}$ lo han hecho en actividades precarias informales, con más de la tercera parte de empleos generados, particularmente en comercio, restaurantes y hoteles,

40 La precarización del trabajo también influye en el tipo de contratación de los trabajadores, debido a quela forma de contratarse definela estabilidad del empleo y el tipo de prestaciones a las que puede acceder o no el trabajador. En 2002,51\% dela población ocupada asalariada (12.7 millones de personas) se contrató mediante contratación temporal y verbal, de este grupo, 83.5\% no gozó de las prestaciones de ley; sólo 1.8\% (más de 227 mil personas) contó con seguridad social (Juárez, 2004:4, 8-9).

\section{Desparrollo}




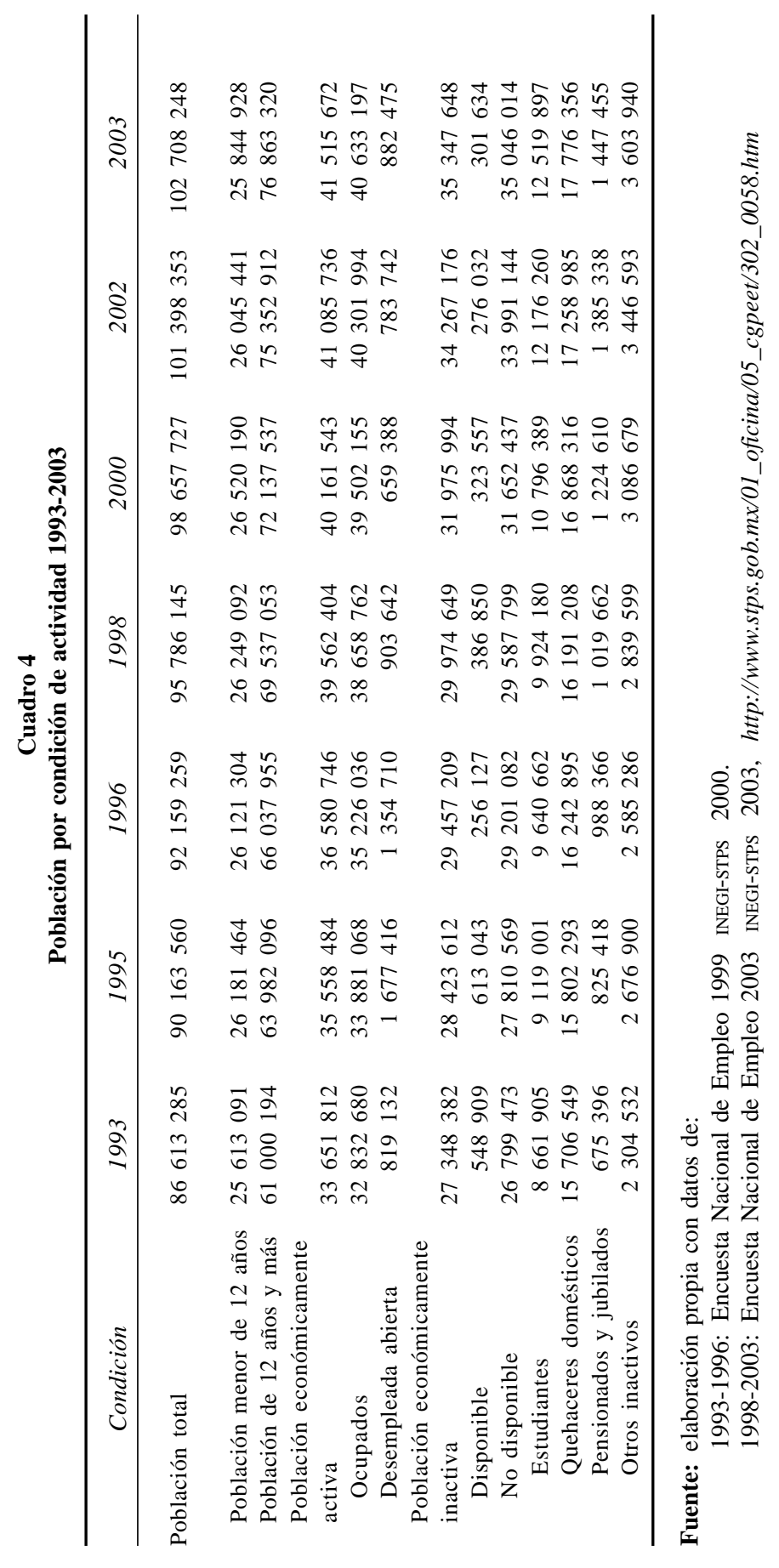


Cuadro 5

Población trabajadora registrada en el IMSS y el ISSSTE 1994-2002 (miles)

\begin{tabular}{lccccccccc}
\hline Descripción & 1994 & 1995 & 1996 & 1997 & 1998 & 1999 & 2000 & 2001 & 2002 \\
\hline $\begin{array}{l}\text { PEA total } \\
\begin{array}{l}\text { Trabajadores } \\
\text { del IMSS }\end{array}\end{array}$ & 27166 & 27347 & 28282 & 29342 & 39562 & 39648 & 40161 & 40072 & 41085 \\
$\begin{array}{l}\text { Trabajadores } \\
\text { del ISSSTE }\end{array}$ & 2150 & 210932 & 11895 & 12714 & 13611 & 14560 & 15240 & 15131 & 15312 \\
\hline \begin{tabular}{l} 
Total $^{\mathrm{c}}$ \\
\hline
\end{tabular} & 13711 & 13112 & 14083 & 14935 & 15886 & 16864 & 17578 & 17500 & 17712 \\
\hline
\end{tabular}

${ }^{\text {e }}$ Cifras estimadas

${ }^{\text {a }}$ Incluye asegurados permanentes y eventuales.

${ }^{\mathrm{b}}$ Incluye asegurados permanentes y eventuales. Se refiere a servidores públicos afiliados al régimen del ISsSTE.

c Suma de asegurados del imss y del IssSTE.

Fuente: Instituto Mexicano del Seguro Social (IMSS) Instituto de Seguridad Social al Servicio de los Trabajadores del Estado (ISsste), en Hugo Ortiz Dietz, México: Banco de Datos 2002-2003, México, El Inversionista Mexicano, 2003, Cuadro K14.

$38 \%$; manufactura, $23 \%$; servicios comunales, sociales y personales, $17 \%$; y construcción, 16.8 \% (INEGI, 2004a:45). Esta situación demuestra cómo la fuerza de trabajo que se incorpora al mercado de trabajo ratifica caminos que ya señalamos. Se pueden incorporar al mercado formal, informal, emigrar o incrementar el ejército de desempleados.

\section{Conclusiones}

Podemos asegurar que el incremento del desempleo y la ampliación de la informalidad han proporcionado elementos para un deterioro conjunto del mercado de trabajo. Todos los trabajadores se ven en la necesidad de aceptar empleos precarios que el mercado ofrece, incluso, modificaciones a conquistas laborales mediante flexibilización que imponen las necesidades de las nuevas condiciones de valoración. A estas últimas se incorporan reformas a las relaciones laborales con las modificaciones en los contratos colectivos de trabajo, las cuales afectan prestaciones sociales aportadas por el Estado (subsidios), bajos salarios, jornadas de trabajo más largas, recortes de personal, eliminación de cláusulas contractuales (asistencia, puntualidad, antigüedad, capacitación y productividad), además del establecimiento de multifunciones y calificación permanente. Estos y otros aspectos ya se aplican en la cotidianidad, aunque todavía no se hayan legalizado pues la reforma laboral aún no se aprueba en el Congreso de la Unión. Una vez que concluya este proceso, culminará el deterioro histórico de condiciones de vida y trabajo de la mayoría de los mexicanos. Los cambios son favorables a necesidades estratégicas de empresas transnacionales y nacionales en el contexto de la globalización económica.

Desde nuestro punto de vista, es urgente la aplicación de una política económica que tenga por objetivo la generación de empleos bien remunerados con inversiones públicas

\section{Desarestrollo}


productivas que dinamicen el mercado interno, mediante inversión en grandes obras de infraestructura, construcción de viviendas, o el incentivo para la producción de bienes, además de revertir la política que ha deteriorado el nivel salarial. Por el contrario, se necesita establecer medidas para incrementar el poder adquisitivo de los trabajadores y activar la economía en su conjunto. No se puede seguir apostando a que nuestra competitividad siga recayendo en el deterioro de las condiciones laborales y del nivel de vida de la población mexicana.

\section{Bibliografía}

Alarcón González, Sandra, El tianguis global. La inserción de los comerciantes callejeros en las cadenas globalizadas de venta, México, tesis Universidad Iberoamericana, 2002, $190 \mathrm{pp}$.

Barba García, Héctor, "Contenido y alcances de las iniciativas de reforma laboral de la UNT y de los sindicatos corporativos y empresariales", en Arturo Alcalde Justiniani et al., Reforma laboral, México, IIEC-UnAm, 2003, pp. 41-52.

Carnoy, Martín, El trabajo flexible en la era de la información, Madrid, Alianza, 2001, 280 pp.

CEESP, La economía subterránea en México, México, Centro de Estudios Económicos del Sector Privado A.C., 1986, 93 pp.

Chavarín Rodríguez, Rubén A.; Víctor M. Castillo Girón y Gerardo Ríos Almodóvar, Mercados regionales de trabajo y empresa, México, Universidad de Guadalajara-UCLA, Juan Pablos Editor, 1999, 198 pp.

Chomsky, Noam y Heinz Dieterich, La sociedad global, México, Joaquín Mortiz, 1999, 197 pp.

Coriat, Benjamín, El taller y el cronómetro (ensayo sobre el taylorismo, el fordismo y la producción en masa), México, Siglo XxI, 12a. edición, 2000, 204 pp.

Damián, Araceli, Cargando el ajuste: los pobres y el mercado de trabajo en México, México, El Colegio de México, 2002, 349 pp.

De la Garza, Enrique, Reestructuración productiva y respuesta sindical en México, México, IIEcUNAM, 1993.

—_ y Alfonso Bouzas, "Flexibilidad del trabajo y contratación colectiva en México", en Revista Mexicana de Sociología, vol. 60, núm. 3, Instituto de Investigaciones Sociales, julioseptiembre, 1998, pp. 87-122.

Dussel, Enrique, "El reto del empleo en México. Cambio estructural en el empleo durante 1982-1992", en Investigación Económica, vol. LV, núm. 212, México, FE-UNAM, abril-junio, 1995, pp. 135-175.
—_ La economía de la polarización. Teoría y evolución del cambio estructural de las manufacturas mexicanas (1988-1996), México, UNAM, Editorial Jus, 1997, 326 pp.

Fajnzylber, Fernando, La industrialización trunca de América Latina, México, Editorial Nueva Imagen, 1983, 416 pp.

Garavito Elías, Rosa Albina, "El impacto sobre las condiciones de trabajo del Proyecto Abascal", en Arturo Alcalde Justiniani et al., Reforma laboral, México, IIEC-UNAM, 2003, pp. 185-204.

Instituto Nacional de Estadística, Geografía e Informática (INEGI), El subsector informal en México, Comunicado de Prensa, Aguascalientes, 05 de septiembre de 2003, Número 100/2003, Comunicación Social, 2003, INEGI.

_ La ocupación en el sector no estructurado en México 1995-2003, Aguascalientes, INEGI, 2004a, 173 pp.

__ Resultado de la encuesta nacional de empleo en el segundo trimestre de 2004, Comunicado de Prensa, Aguascalientes, 13 de agosto de 2004, Número 101/2004, Comunicación Social, Instituto Nacional de Estadística, Geografía e Informática (INEGI), 2004b, 8 pp.

Juárez Sánchez, Laura, Reestructuración económica $y$ trabajadores del campo y de la ciudad, en http://www.uom.edu.mx/Reestructuración Economica.htm, 2004

Manzo Ramos, Eduardo, "Del incierto trabajo a la precariedad asegurada. Tendencias y retos de la ocupación en México", en El Cotidiano, año 16, núm. 99, enero-febrero, México, UAM, 2000, pp. 42-54.

Marx, Carlos, "Capítulo XXIII. La ley general de la acumulación capitalista", El Capital, tomo I, vol. 3, México, Siglo xxi, 2000, pp. 759-808.

Organización Internacional del Trabajo, "El trabajo decente y la economía informal" en Conferencia Internacional del Trabajo, 90a. Reunión, Ginebra, 2002, 147 pp.

\section{Desaarrollo}


Informe General, Decimoséptima Conferencia Internacional de Estadísticos del Trabajo, Organización Internacional del Trabajo, Ginebra, OIT, 2003.

Pries, Ludger, "Teoría sociológica del mercado de trabajo" en Enrique de la Garza Toledo (coordinador), Tratado Latinoamericano de sociología del trabajo, México, El Colegio de México, 2000, pp. 511-537.

Rendón Gan, Teresa, Trabajo de hombres y trabajo de mujeres en el México del siglo XX, México, CRIM-PUEG, 2004, 283 pp.

y Carlos Salas, El cambio en la estructura de la fuerza de trabajo en América Latina" en Enrique de la Garza Toledo (coordinador), Tratado latinoamericano de sociología del trabajo, México, El Colegio de México, 2000a, pp. 540-565.

y Graciela Bensusán, Trabajo y trabajadores en el México contemporáneo, México, Miguel Ángel Porrúa, 2000b, pp. 221.

Reuben-Soto, William, "Reestructuración del sistema financiero internacional", en Deuda Externa y Alternativas. Escenario Internacional. La deuda externa e interna en México, México, Red Mexi- cana de Acción Frente al Libre Comercio (RMALC), 1995, pp. 17-26.

Rivera Ríos, Miguel Ángel, México en la economía global. Tecnología, espacio e instituciones, México, UNAM, 2000, 212 pp.

Salas P., Carlos, “¿Pequeñas unidades económicas o sector informal?, en El Cotidiano, año 7, núm. 45, México, UAM, enero-febrero, 1992, pp. 24-31.

y Eduardo Zepeda, "Empleo y salarios en México contemporáneo", en Enrique de la Garza y Carlos Salas (coordinadores), La situación del trabajo en México, México, Instituto de Estudios del Trabajo, UAM, Plaza y Valdés, 2003, pp. 55-75.

Saxe-Fernandez, John, La compra-venta de México. Una interpretación histórica y estratégica de las relaciones México-Estados Unidos, México, Plaza \& Janés, 2002, 598 pp.

Sennett, Richard, La corrosión del carácter. Las consecuencias personales del trabajo en el nuevo capitalismo, México, Anagrama, 5a. edición, 2001, $188 \mathrm{pp}$

Valle Baeza, Alejandro, “¿Está derrotado el marxismo?, en Metrópolis, núm. 4, julio, www.revistametropolis.com, 2004.

\section{Desarrollo}

